\title{
IMPLANTAÇÃO DE PROJETOS DE REUSO DE EFLUENTES NO NORDESTE BRASILEIRO
}

\author{
Daris Correia dos Santos ${ }^{1}$
}

\author{
Raimundo Mainar de Medeiros ${ }^{2}$
}

\section{Verônica Gabriella de Oliveira ${ }^{3}$}

RESUMO: Este artigo apresenta uma proposta de um modelo de ações que visa fornecer a cidades de pequeno porte as melhores condições sanitárias para provimento do bem estar socioambiental, atendendo simultaneamente às legislações ambientais vigentes, tomando como referência o sucesso das experiências referentes ao reuso de efluentes para fins agrícolas, através de uma análise dos projetos implantados, os quais visam à reciclagem das águas residuais. A metodologia adotada teve como base pesquisas nacionais e internacionais na temática de reuso de água e memorial de cálculo para a implantação de projetos de tratamento de efluentes. Através do modelo de tratamento de águas residuais integrado ao reuso agrícola destinados para projetos de cidades com até 20.000 habitantes, que não possuem uma destinação adequada para os efluentes gerados verificou-se que as características similares de clima e escassez de água que existem entre Israel e a região do semiárido brasileiro podem, em princípio, levar a crer

\footnotetext{
${ }^{1}$ Engenheira Sanitarista e Ambiental, Mestranda em Meteorologia, Universidade Federal de Campina Grande, PB, dariscorreia@gmail.com

2 Meteorologista, Doutorando em Meteorologia, Universidade Federal de Campina Grande, PB, e-mail: mainarmedeiros@gmail.com

3 Graduanda em Meteorologia, Universidade Federal de Campina Grande, PB, e-mail: oliver.gabzinha@hotmail.com
} 

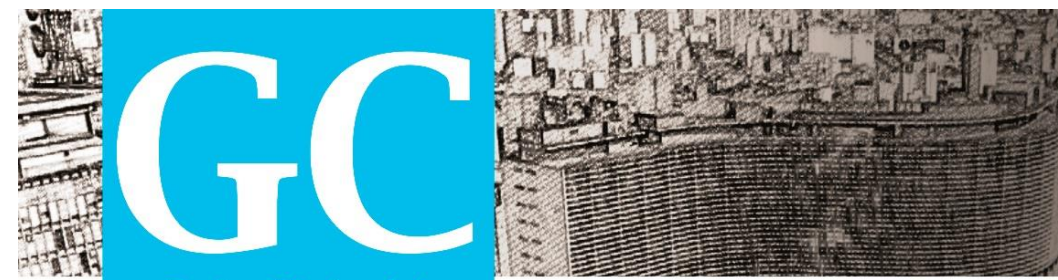

Revista Nacional de

Gerenciamento de Cidades

que a experiência bem sucedida deste país, no campo da agricultura irrigada, utilizando águas residuais, poderá ser facilmente repetida no Brasil. A utilização das águas residuais na agricultura favorece a continuidade na produção agrícola em localidades que não possuem outra fonte de água durante a estação seca a não serem esgotos. Diante do exposto, a implantação de uma estação de tratamento de efluentes e de sistemas de irrigação adequados garante o sucesso de reuso de efluentes.

Palavras-Chave: Recursos hídricos. Águas residuais. Nordeste brasileiro

\section{INTRODUÇÃO}

Os conhecimentos internacionais e nacionais de reuso de efluentes, associados a atitudes prudentes de aplicação com novos estudos e pesquisas sendo desenvolvidos, estimulam a implementação da técnica de reuso com competência. Conforme Van Der Hoek et al. (2002), as maiores vantagens do aproveitamento da água residuária para fins agrícolas residem na conservação da água disponível e na possibilidade de aporte e reciclagem de nutrientes (reduzindo a necessidade de fertilizantes químicos), concorrendo para a preservação do meio ambiente.

Este artigo apresenta uma proposta de um modelo de ações com foco no desenvolvimento da agricultura sustentável na região do semiárido nordestino do Brasil, tomando como referência o sucesso das experiências, referente ao reuso de esgotos para fins agrícolas, através de uma análise dos projetos implantados, os quais visam à reciclagem das águas residuais. O sistema proposto para o tratamento de efluentes destinados a cidades com até 20.000 habitantes, que não possuem uma destinação adequada para os efluentes gerados é composto por grade, caixa de areia, calha Parshall e lagoas de estabilização, pois, de acordo com pesquisas de informações básicas municipais do Instituto Brasileiro de Geografia e Estatística- IBGE (2011), a presença de esgoto a céu aberto prejudica comunidades em 1.031 municípios brasileiros (46\%), na região Nordeste, o estado com mais municípios com pelo menos um impacto ambiental relevante é Pernambuco, onde $82 \%$ deles têm esgoto a céu aberto. 

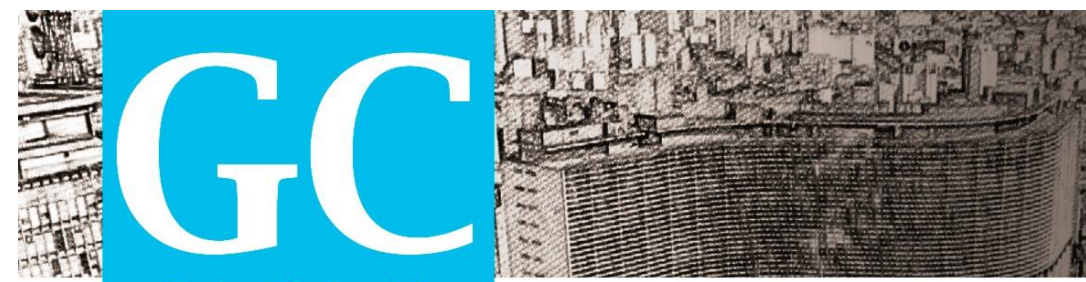

Revista Nacional de

Gerenciamento de Cidades

\section{EXPERIÊNCIAS DE REUSO DE EFLUENTES}

O reuso de águas servidas é uma prática difundida no México. O país tem problemas de disponibilidade de água em vista de sua distribuição geográfica, clima, além da contaminação de suas águas. O uso agrícola de águas residuais para irrigação no Vale do Mezquital data do final do século XIX, como consequência das obras de drenagem do Vale do México. Essas águas constituem um recurso valioso e são destinadas a regiões áridas e semiáridas, cada vez com maior eficiência e segurança para a saúde humana e proteção do meio ambiente. No Vale do Mezquital, a principal atividade econômica da população é a agricultura, complementada pela criação de gado. De acordo com Alvarez (2011), a região apresenta um exemplo único do reuso para a irrigação, devido a grande área cultivada (83.000 ha entre 1993 e 1994) e ao longo tempo de experiência na utilização das águas residuais para a irrigação.

Israel foi pioneiro em utilizar água de reuso na irrigação, seguido por Tunísia, Chipre e Jordânia (ANGELAKIS e BONTOUX, 2001). Em Israel está sendo reutilizado mais de $70 \%$ do volume total de águas das redes de esgotos urbanos. O projeto da região de Dan demonstra a possibilidade de converter o deserto de Negev em uma área fértil e produtiva para a agricultura, através do aproveitamento das águas residuais.

O reuso na Tunísia mostra-se prioritário na gestão dos recursos hídricos em função da escassez de água e do aumento da poluição (BAHRI, 1998). Os programas de reuso no país remontam à década de sessenta, o que coloca esta região entre as poucas nações do mediterrâneo que têm uma política federal de reuso em plena atividade.

Por ser um país que tem problemas com escassez de água, a África do Sul tem grande interesse na utilização de águas residuais. O país considera as águas provenientes do reuso como um recurso adicional para suprir as necessidades da sua população (ODENDAAL et al 1998). As pesquisas sobre o assunto no país remontam a década de 60 e estão direcionadas no princípio às condições geográficas, uma vez que as maiores cidades estão localizadas longe do mar. 

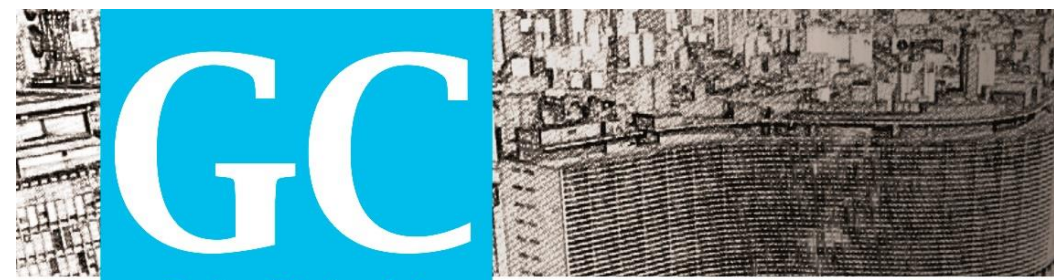

Revista Nacional de

Gerenciamento de Cidades

\section{METODOLOGIA}

A região Nordeste do Brasil está situada logo abaixo do Equador, ocupando a posição norte oriental do País, entre $1^{\circ}$ e $18^{\circ} 30^{\prime}$ de latitude Sul e $34^{\circ} 20^{\prime}$ e $48^{\circ} 30^{\prime}$ de longitude oeste. Ocupa uma área de 1.561.177,8 km², o que representa 18,3\% do território brasileiro e é a região mais subdividida politicamente pais, Figura 1, com nove estados: Alagoas, Bahia, Ceará, Paraíba, Pernambuco, Piauí, Rio Grande do Norte e Sergipe (GARCIA \& GARAVELLO, 1996). Quanto ao relevo, sua porção oriental é dominada por superfícies tabulares e chapadas cristalinas, como a Borborema e Diamantina.

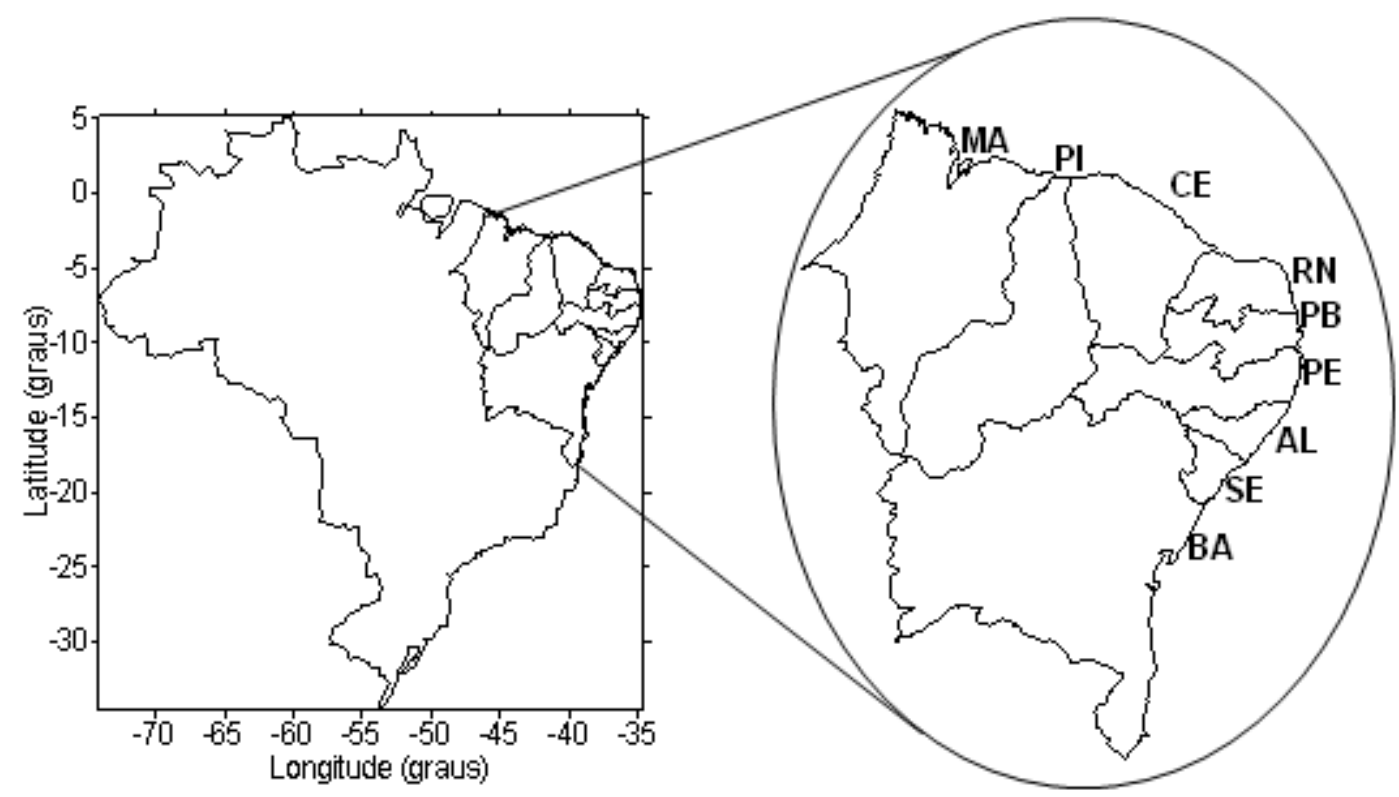

Figura 1. Localização do Nordeste do Brasil (NEB). Fonte: Autor (2013)

A metodologia adotada se fundamentou em pesquisas nacionais e internacionais na temática de reuso de água e em um memorial de cálculo para implantação de um projeto de uma Estação de Tratamento de Efluentes- ETE para cidades de pequeno porte.

Este projeto foi desenvolvido tomando como base o crescimento populacional de $1,05 \%$ ao ano segundo dados do IBGE, sendo projetado para uma perspectiva de 20 anos de funcionamento acompanhando o desenvolvimento populacional. A região nordeste possui uma temperatura média mínima de $25^{\circ} \mathrm{C}$, o que é definitivo para escolha 


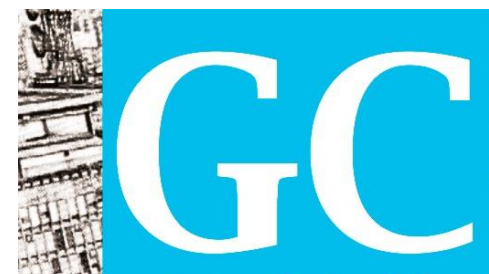

Revista Nacional de

Gerenciamento de Cidades

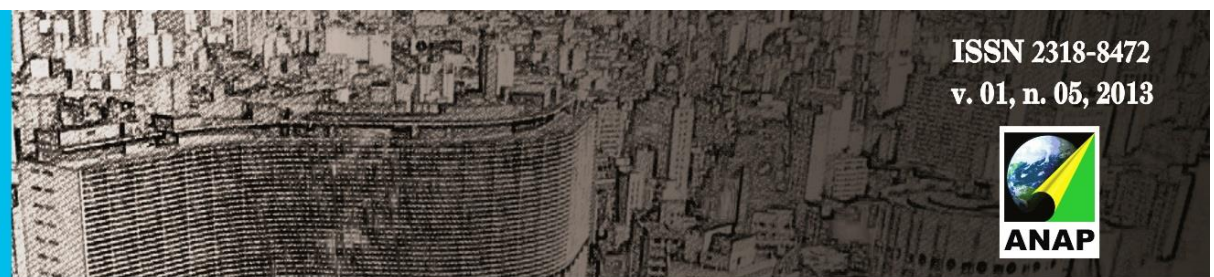

v. 01, n. 05,2013

ANAP

do processo de tratamento dos efluentes, o que indica um tratamento que possa aproveitar essa temperatura para aceleração do processo de tratamento. Considerando o tempo de vida útil de 20 anos para o referido projeto têm-se os dados referentes à população de projeto, Quadro1.

Quadro 1: Perspectiva de crescimento para implantação do projeto sugerido.

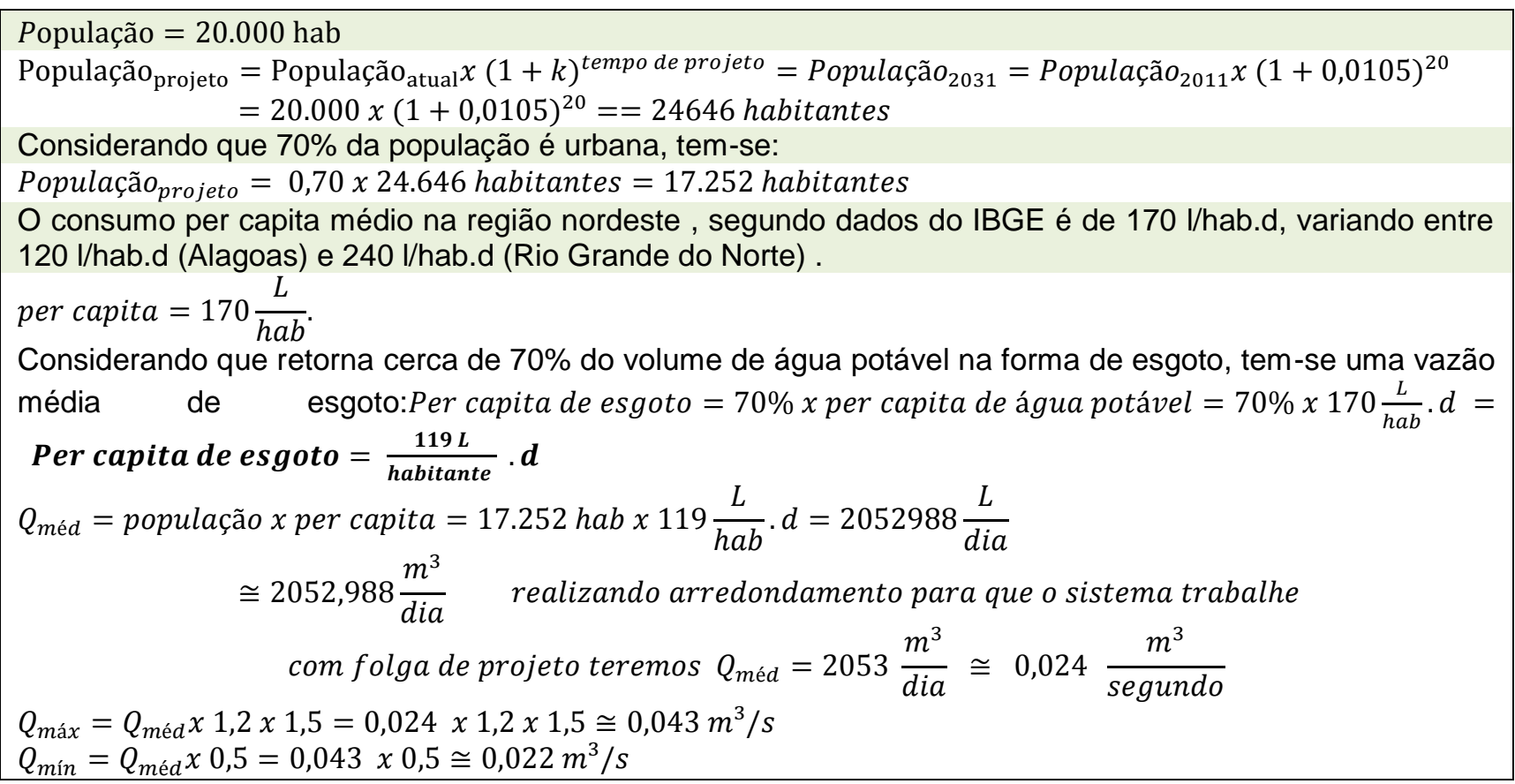

Fonte: Autor (2013)

O pré-tratamento deverá ser concebidos para suportar vazões de final de plano, Tabela 1.

Tabela 1. Vazões do Projeto para o projeto com vida útil de 20 anos.

\begin{tabular}{lll}
\hline & $\begin{array}{l}20 \text { anos } \\
\text { Para o ano de } 2031 \\
\text { (L/dia) }\end{array}$ & $\begin{array}{l}20 \text { anos } \\
\text { Para o ano de } 2031 \\
\left(\mathrm{~m}^{3} / \mathrm{s}\right)\end{array}$ \\
\hline$Q_{\text {máxima }}$ & 3695378,4 & 0,043 \\
$Q_{\text {média }}$ & 2.052 .988 & 0,024 \\
$Q_{\text {mínima }}$ & 1026494 & 0,022 \\
\hline
\end{tabular}

Fonte: Autor (2013) 


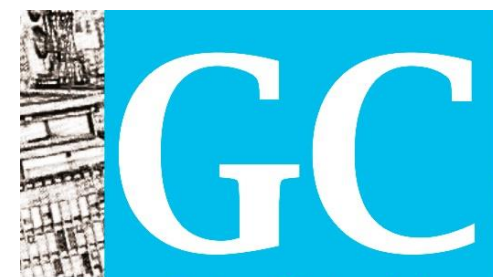

Revista Nacional de

Gerenciamento de Cidades

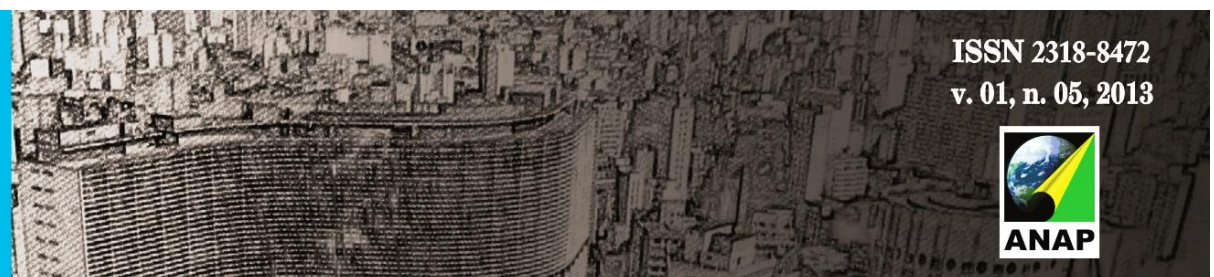

\section{O dimensionamento das partes componentes da ETE seguiu a seguinte sequência}

de cálculo, considerando a vazão final de projeto. O projeto foi dimensionado de acordo com o memorial de cálculo a seguir, Quadro 2.

Quadro 2. Memorial de cálculo da estação de tratamento de efluentes-ETE, proposta para municípios de pequeno porte.

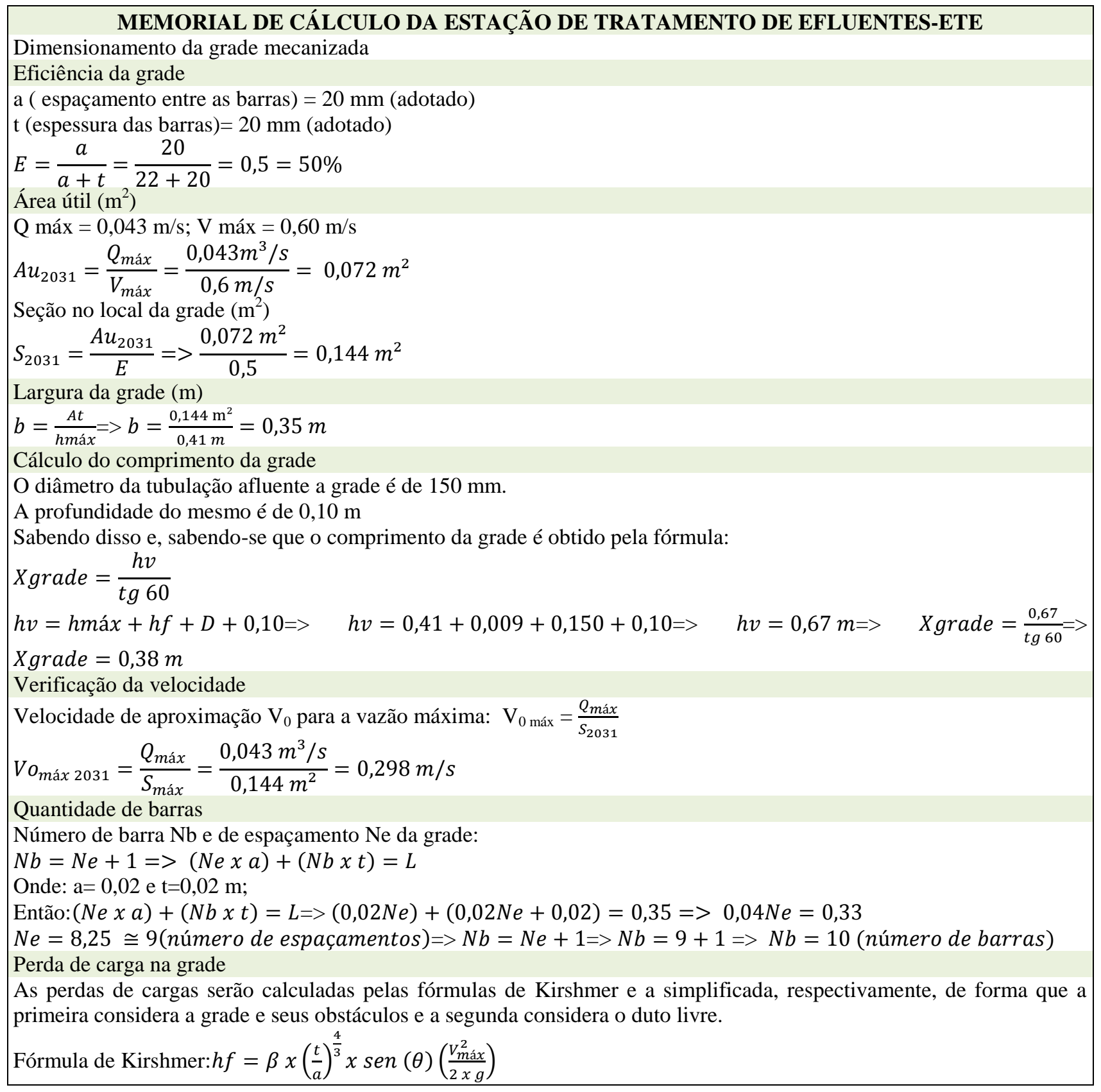


Onde $\beta$ é o valor de referência para cada seção das barras, de acordo com o tipo de barra retangular escolhida: $\beta=2,42$ e

$f=\beta x\left(\frac{t}{a}\right)^{\frac{4}{3}} x \operatorname{sen}(\theta)\left(\frac{V_{\text {máx }}^{2}}{2 \times g}\right)=2,42 \times\left(\frac{1,0}{2,5}\right)^{\frac{4}{3}} x \operatorname{sen}(75) \times\left(\frac{\left(0,42 \frac{m}{s}\right)^{2}}{2 \times 9,8 \frac{m}{s^{2}}}\right)$

$h f=1,42 m$

Fórmula simplificada:

$h f=1,43 \times\left(\frac{V_{\text {máx }}^{2}-V o_{\text {máx }}^{2}}{2 \times g}\right)=1,43 \times\left(\frac{(0,6)^{2}-\left(0,42 \frac{m}{s}\right)^{2}}{2 \times 9,8 \mathrm{~m} / \mathrm{s}^{2}}\right)=0,009 \mathrm{~m}$

Desarenador e medidor Parshall

Comprimento da caixa de areia

$L=22,5(h m e ́ d-z)$

$L=22,5(0,27-0,103)$

$L=3,75 \mathrm{~m}$

Largura do canal

Adota-se a velocidade $\mathrm{u}=0,30 \mathrm{~m} / \mathrm{s}(\mathrm{ABNT}, 1992)$ para determinar a largura do canal (b).

$b=\frac{Q \text { méd }}{\text { uméd }(\text { hméd }-z)}$

$b=\frac{0,024}{0,30(0,27-0,103)}$

$b=0,48 \mathrm{~m}$

Taxa de escoamento superficial

$q=\frac{Q m e ́ d}{B x L}=\frac{2073,6}{3,75 \times 0,48}=1.152 \mathrm{~m}^{3} / \mathrm{m}^{2} /$ dia

Logo, são calculadas as alturas máxima, média e mínima pela equação de Azevedo Neto.

$h_{\text {máx }}=\left[\frac{Q_{\text {máx }}}{2,2 \times W}\right]^{\frac{2}{3}}=\left[\frac{0,043 \mathrm{~m}^{3} / \mathrm{s}}{2,2 \times 0,076 \mathrm{~m}}\right]^{\frac{2}{3}}=0,41 \mathrm{~m}$

$h_{\text {méd }}=\left[\frac{Q_{\text {méd }}}{2,2 \times W}\right]^{\frac{2}{3}}=\left[\frac{0,024 \mathrm{~m}^{3} / \mathrm{s}}{2,2 \times 0,076 \mathrm{~m}}\right]^{\frac{2}{3}}=0,27 \mathrm{~m}$

$h_{\text {min }}=\left[\frac{Q_{\text {min }}}{2,2 \times W}\right]^{\frac{2}{3}}=\left[\frac{0,022 \mathrm{~m}^{3} / \mathrm{s}}{2,2 \times 0,076 \mathrm{~m}}\right]^{\frac{2}{3}}=0,26 \mathrm{~m}$

Cálculo do rebaixo

$Z=\frac{Q_{\text {máx }} \times h_{\text {min }}-Q_{\text {min }} \times h_{\text {máx }}}{Q_{\text {máx }}-Q_{\text {mín }}}=\frac{0,043 \frac{\mathrm{m}^{3}}{\mathrm{~s}} \times 0,26 \mathrm{~m}-0,022 \frac{\mathrm{m}^{3}}{\mathrm{~s}} \times 0,41 \mathrm{~m}}{0,043-0,022 \frac{\mathrm{m}^{3}}{\mathrm{~s}}}=0,103 \mathrm{~m}$

Velocidades máximas e mínimas

velocidade máxima $=\frac{Q \text { máx }}{b(\text { Hmáx }-z)}$

velocidade máxima $=\frac{0,043}{0,48(0,41-0,103)}$

velocidade máxima $=0,30 \frac{\mathrm{m}}{\mathrm{s}}$

velocidade mínima $=\frac{Q \stackrel{\mathrm{s}}{\min }}{b(h \min -z)}$

velocidade mínina $=\frac{0,022}{0,48(0,26-0,103)}$

velocidade mínima $=0,30 \mathrm{~m} / \mathrm{s}$

Níveis da água na calha $\left(\mathrm{h}_{1}, \mathrm{~h}_{2} \mathrm{e} \mathrm{h}_{3}\right)$ : 


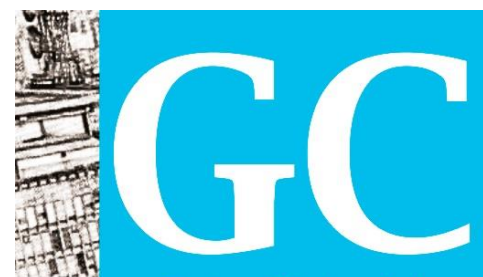

Revista Nacional de

Gerenciamento de Cidades

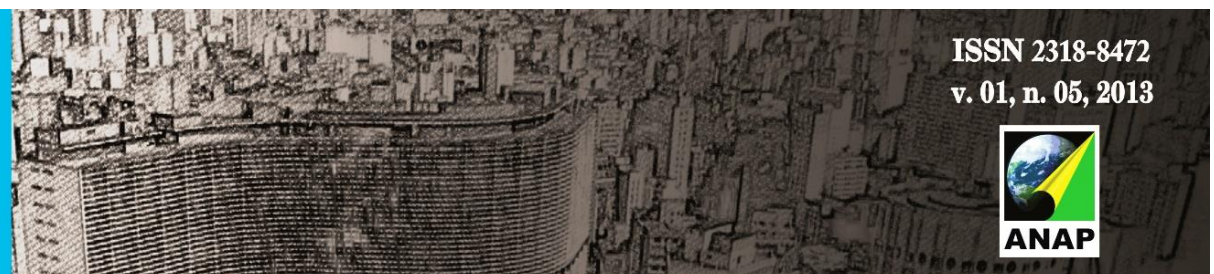

$h=h_{\text {méd }}=0,27 \mathrm{~m}$

$h_{2}=0,7 \times h=0,7 \times 0,27 m=0,189 m$

$h_{3}=h=0,27 \mathrm{~m}$

$h f=h-h_{2}=0,27 m-0,189 m=0,081 m$

Calculando o rebaixamento $(\mathrm{M})$, onde $\mathrm{K}+\mathrm{M}=\mathrm{h}_{3}-\mathrm{h}_{2}$

$M=h_{3}-h_{2}-K=0,27 m-0,189 m-0,025=0,056 m$

$N A_{3}=h_{3}=0,27 \mathrm{~m}$

$N A=N A_{3}+h f=0,27 m+0,081 m=0,351 m$

Lagoa anaeróbia

Carga afluente de DBO é de:

Carga $=$ DBOafluente $*$ Qméd

Carga $=\frac{300 \frac{m g}{l} \times 2052988 \frac{l}{\text { dia }}}{10^{6}} \Rightarrow$ Carga $=615,89 \mathrm{Kg}$ de DBO $/ \mathrm{d}$

A taxa de aplicação volumétrica $\left(\mathrm{L}_{\mathrm{V}}\right)$, segundo Sperling é dada pela equação $(0,01 \mathrm{~T}-0,10)$, onde $\mathrm{T}$ é a temperatura média, logo:

$\mathrm{L}_{\mathrm{V}}=0,01 \mathrm{~T}-0,10=(0,01 \mathrm{X} 25)-0,10 \Rightarrow \mathrm{L}_{\mathrm{V}}=0,15 \mathrm{Kg}$ de $\mathrm{DBO} / \mathrm{m}^{3} . \mathrm{d}$

Cálculo do volume requerido:

$\mathrm{V}=\frac{\text { Carga }}{\mathrm{L}_{\mathrm{V}}}=\frac{615,89 \mathrm{Kg} \text { de DBO } / \mathrm{d}}{0,15 \mathrm{Kg} \text { de } \mathrm{DBO} / \mathrm{m}^{3} \cdot \mathrm{d}} \Rightarrow \mathrm{V}=4105,976 \mathrm{~m}^{3}$

Para TDH:

$\mathrm{TDH}_{2031}=\frac{\mathrm{V}}{\mathrm{Q}_{2031}}=\frac{4105,976 \mathrm{~m}^{3}}{22052,988 \mathrm{~m}^{3} / \text { dia }} \Rightarrow \mathrm{TDH}_{2030}=2,00 \mathrm{~d}$

Determinando as possíveis dimensões na lagoa anaeróbia, adotando uma profundidade de $\mathrm{h}=5 \mathrm{~m}$, vamos ter:

$\mathrm{A}=\frac{\mathrm{V}}{\mathrm{h}}=\frac{4105,976 \mathrm{~m}^{3}}{5 \mathrm{~m}} \Rightarrow \mathrm{A}=821,19 \mathrm{~m}^{2}$

As possíveis dimensões da lagoa anaeróbia é, largura de 19,00 m e comprimento de 45,00 m, L/B=2,5. A inclinação dos taludes internos é de 1:3

Comprimento:

Comprimento de fundo $=\mathrm{L}-\mathrm{d} . \mathrm{h}=45-(2,5 \mathrm{X} 5)=32,50 \mathrm{~m}$

Comprimento do nível da água $=\mathrm{L}+\mathrm{d} \cdot \mathrm{h}=45+(2,5 \mathrm{X} 5)=57,50 \mathrm{~m}$

Comprimento na crista do talude $=$ Comprimento no nível da água +2 .d.(borda livre)

Comprimento na crista do talude $=57,50+2 \times 2,5 \times 0,6=60,50 \mathrm{~m}$

Larguras:

Largura do fundo $=\mathrm{B}-$ d.h $=19,00-(2,5 \mathrm{X} 5)=6,5 \mathrm{~m}$

Largura no nível da água $=\mathrm{B}+\mathrm{d} . \mathrm{h}=19,00+(2,5 \mathrm{X} 5)=31,50 \mathrm{~m}$

Largura na crista do talude $=$ Largura no nível da água +2. . .(borda livre)

Largura na crista do talude $=31,50+2 \times 2,5 \times 0,6=34,50 \mathrm{~m}$

Concentração de DBO na saída da lagoa anaeróbia, adotando uma eficiência de $60 \%$ :

$\mathrm{DBO}_{\mathrm{S}}=\left(\frac{100-\mathrm{E}}{100}\right) \times \mathrm{DBO}_{\mathrm{o}}=\left(\frac{100-60}{100}\right) \times 300 \Rightarrow \mathrm{DBO}_{\mathrm{S}}=120 \mathrm{mg} / \mathrm{L}$

O efluente da lagoa anaeróbia e o afluente da lagoa facultativa secundária.

Acumulo do lodo na lagoa anaeróbia, adotando-se uma taxa de acumulação de $0,04 \mathrm{~m}^{3} / \mathrm{hab}$.ano ( segundo Sperling), tem-se:

Acumulação em $2031=0,04 \mathrm{~m}^{3} /$ hab.ano X 17.252 hab

Acumulação $=690,08 \mathrm{~m}^{3}$ durante um ano

A espessura da camada de lodo em 1 ano:

Espessura $=\frac{\text { acumulaçao }}{\text { área } X \text { tempo }}=\frac{690,08 \mathrm{~m}^{3}}{938,51 \mathrm{~m}^{2} \mathrm{X} 1 \mathrm{ano}} \Rightarrow$ Espessura $=0,73 \mathrm{~m} \mathrm{em} 1$ ano.

Essa grande taxa de acumulação de lodo se deve ao baixo tempo de detenção na lagoa e por ser bem profunda.

O tempo para se atingir $1 / 3$ da altura útil da lagoa:

Tempo $=\frac{\mathrm{h} / 3}{\text { Espessura }}=\frac{5 \mathrm{~m} / 3}{0,73 \mathrm{~m} / \text { ano }} \Rightarrow$ Tempo $\approx 2,28$ anos.

O volume de lodo a ser retirado a cada limpeza da lagoa anaeróbia vai ser de, o volume corresponde a 1/3 do volume útil da lagoa.

$\mathrm{V}_{\text {lodo }}=\frac{\mathrm{V}}{3}=\frac{4105,976}{3} \Rightarrow \mathrm{V}_{\text {lodo }}=1368,66 \mathrm{~m}^{3}$ 

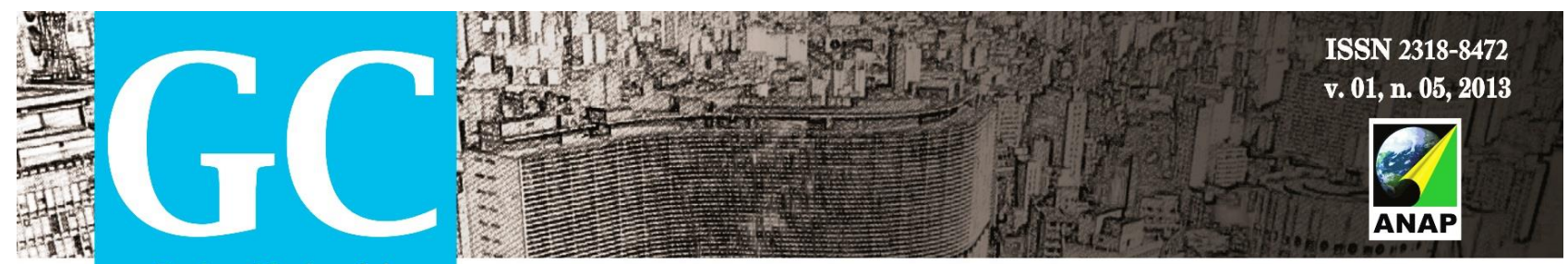

Revista Nacional de

Gerenciamento de Cidades

Lagoa facultativa secundária

Carga afluente a lagoa facultativa:

Essa carga é o efluente da lagoa anaeróbia, com a eficiência de remoção na lagoa anaeróbia de $60 \%$ logo a carga afluente a lagoa facultativa é:

Para 2031, temos uma carga de:

$\mathrm{L}_{2031}=\frac{(100-\mathrm{E}) \times \mathrm{L}_{\mathrm{O}}}{100}=\frac{(100-60) \times 615,89 \mathrm{KgDBO} / \mathrm{d}}{100} \Rightarrow \mathrm{L}_{2031}=246,35 \mathrm{~kg} \mathrm{de} \mathrm{DBO} / \mathrm{d}$

Taxa de aplicação superficial $\left(\mathrm{T}=25^{\circ} \mathrm{C}\right)$ :

$L s=350 x(1,107-002 T)^{T-25}$

$\mathrm{L}_{\mathrm{S}}=350 \mathrm{Kg}$ de DBO/ha.d

Área requerida da lagoa facultativa

Nesse caso vamos utilizar a carga final de projeto, para se ter ideia de qual o tamanho da área necessária para $\mathrm{p}$ tratamento.

$\mathrm{A}=\frac{\mathrm{L}_{2031}}{\mathrm{~L}_{\mathrm{S}}}=\frac{246,35 \mathrm{Kg} \text { de DBO } / \mathrm{d}}{350 \mathrm{Kg} \text { de DBO } / \text { ha.d }} \Rightarrow \mathrm{A}=0,71 \mathrm{ha}=7038,74 \mathrm{~m}^{2}$

Com uma área de $7038,74 \mathrm{~m}^{2}$, as possíveis dimensões médias, com relação $\mathrm{L} / \mathrm{B}=2,5$; tem-se comprimento

133,00 $\mathrm{m}$ e largura $53 \mathrm{~m}$. Adotando uma profundidade $\mathrm{h}=2 \mathrm{~m}$, logo o volume é de:

$\mathrm{V}=\mathrm{B}$ X L X h = $53 \mathrm{~m} \mathrm{X} 133 \mathrm{~m} \mathrm{X} 2 \mathrm{~m}=>\mathrm{V}=14098 \mathrm{~m}^{3}$

Dimensões

As lagoas vão ter uma inclinação de talude interno vai ser 1:2,5. Logo:

Comprimentos

Comprimento de fundo $=\mathrm{L}-\mathrm{d} \cdot \mathrm{h}=133-(2,5 \mathrm{X} 2)$

Comprimento de fundo $=128,00 \mathrm{~m}$

Comprimento no nível da água $=\mathrm{L}+\mathrm{d} \cdot \mathrm{h}=133+(2,5 \mathrm{X} 2)$

Comprimento no nível da água $=138 \mathrm{~m}$

Comprimento na crista do talude $=$ comprimento no nível da água +2 .d.(borda livre)

Comprimento na crista do talude $=138+2 \times 2,5 \times 0,6$

Comprimento na crista do talude $=141,00 \mathrm{~m}$

Larguras

Largura de fundo $=\mathrm{B}-\mathrm{d} . \mathrm{h}=53-(2,5 \mathrm{X} 2)$

Largura de fundo $=48,00 \mathrm{~m}$

Largura no nível da água $=\mathrm{B}+\mathrm{d} \cdot \mathrm{h}=53,00+(2,5 \mathrm{X} 2)$

Largura no nível da água $=58,00 \mathrm{~m}$

Largura na crista do talude $=$ largura no nível da água +2. d.(borda livre)

Largura na crista do talude $=58,00+2 \times 2,5 \times 0,6$

Largura na crista do talude $=61,0 \mathrm{~m}$

Tempo de detenção hidráulico:

$\mathrm{TDH}=\frac{\mathrm{V}}{\mathrm{Q}_{2031}}=\frac{14098 \mathrm{~m}^{3}}{2052,988 \mathrm{~m}^{3} / \mathrm{d}} \Rightarrow \mathrm{TDH}=6,86 \mathrm{~d}$

Estimativa da DBO solúvel efluente

O tipo de fluxo adotado e o disperso, logo a fórmula da DBO solúvel é $S=S_{o} \frac{4 a e^{\left(\frac{1}{2}\right) d}}{(1+a)^{2} e^{\left(\frac{a}{2}\right) d}-(1-a)^{2} e^{\left(-\frac{a}{2}\right) d}}$,

Número de dispersão:

$d=1 /(L / B)$, onde $\mathrm{L} / \mathrm{B}=2,5$

$\mathrm{d}=0,4$;

Coeficiente de remoção de DBO;

$\mathrm{k}=\mathrm{k}_{20} 0^{(\mathrm{T}-20)}$

$\mathrm{k}\left(25^{\circ} \mathrm{C}\right)=0,35 \mathrm{x}(1,05)^{(25-20)}$

$\mathrm{k}\left(25^{\circ} \mathrm{C}\right)=0,45 \mathrm{~d}^{-1}$

$\mathrm{a}=(1+4 \text { k. t. d })^{0,5}$

$a=(1+4 \times 0,45 \times 6,86 \times 0,5)^{0,5}$

$\mathrm{a}=2,43$

Concentração de DBO solúvel efluente (mg/l): 


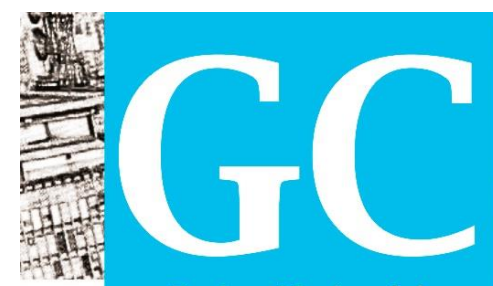

Revista Nacional de

Gerenciamento de Cidades

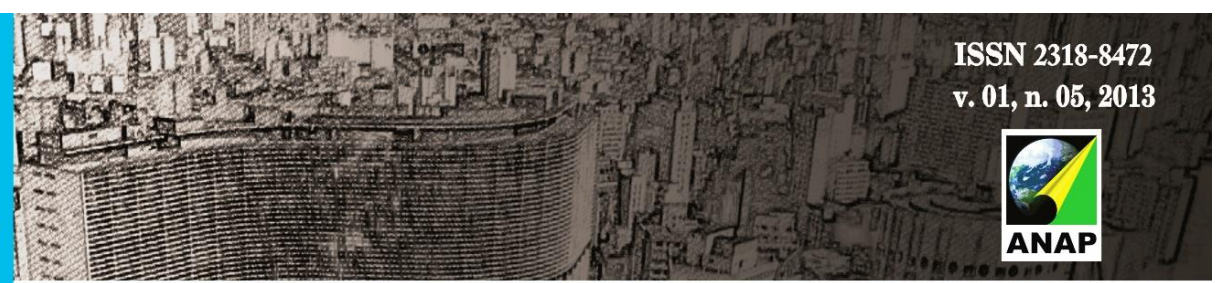

$S=S_{o} \frac{4 a e^{1 / 2 d}}{(1+a)^{2} e^{a / 2 d}-(1-a)^{2} e^{-a / 2 d}}=120 x \frac{4 \times 2,43 e^{1 / 2 \times 0,5}}{(1+2,43)^{2} e^{2,43 / 2 x 0,4}-(1-2,43)^{2} e^{-2,43 / 2 \times 0,4}}=16,58 \mathrm{mg} \mathrm{DBO} / 1$

Estimativa da DBO particulada efluente:

Conforme Von Sperling (1996) para a estimativa da DBO particulada, pode-se assumir uma determinada concentração de SS, na faixa de 60 a $100 \mathrm{mg} / \mathrm{L}$, vamos admitir uma concentração de SS efluente igual a $80 \mathrm{mg} / \mathrm{L}$ e considerando-se que cada $1 \mathrm{mgSS} / \mathrm{L}$ implica numa DBO em torno de $0,35 \mathrm{mg} / \mathrm{L}$.

DBO particulada $=0,35 \mathrm{mg} \mathrm{DBO} / \mathrm{mgSS} \times 80 \mathrm{mg} \mathrm{DBO} / \mathrm{L}$

DBO particulada $=28 \mathrm{mg} \mathrm{DBO} / \mathrm{L}$

DBO total efluente:

$\mathrm{DBO}$ efluente $=\mathrm{DBO}$ solúvel $+\mathrm{DBO}$ particulada $=16,58 \mathrm{mg} \mathrm{DBO} / \mathrm{L}+28 \mathrm{mg} \mathrm{DBO} / \mathrm{L}$

DBO efluente $=44,58 \mathrm{mg}$ DBO$/ \mathrm{L}$

Cálculo da eficiência total do sistema de lagoa anaeróbia e lagoa facultativa na remoção de DBO:

$\mathrm{E}=\frac{\left(\mathrm{S}_{\mathrm{o}}-\text { DBO efluente }\right)}{\mathrm{S}_{\mathrm{o}}} \times 100=\frac{(300-44,58)}{300} \times 100 \Rightarrow \mathrm{E}=85,14 \%$

Área útil total (lagoa anaeróbia e facultativa)

$\mathrm{A}_{\text {util }}=821,19 \mathrm{~m}^{2}+7038,74 \mathrm{~m}^{2} \Rightarrow \mathrm{A}_{\text {util }}=7859,93 \mathrm{~m}^{2}=0,78 \mathrm{ha}$

Área total requerida:

Usando um fator de 1,2 tem-se, a área total ocupada pelo sistema de lagoas e estruturas auxiliares:

$\mathrm{A}_{\mathrm{T}}=1,2 \times \mathrm{A}_{\text {util }}=1,2 \times 0,78 \mathrm{ha} \Rightarrow \mathrm{A}_{\mathrm{T}}=0,94 \mathrm{ha}$

Área per capita $=\frac{7859,93 \mathrm{~m}^{2}}{17.252 \mathrm{hab}} \Rightarrow>$ Área per capita $=0,45 \mathrm{~m}^{2} / \mathrm{hab}$

Lagoa de maturação

Considerar o afluente de coliformes termotolerantes, CTT $=10^{8} \mathrm{CCT} / 100 \mathrm{ml}$ :

Taxa de decaimento de CTT primário, segundo Pearson (1986):

$\mathrm{kt}=2,6(1,19)^{\mathrm{t}-20}$

$\operatorname{kt}\left(25^{\circ} \mathrm{C}\right)=2,6 x(1,19)^{25-20}$

$\operatorname{kt}\left(25^{\circ} \mathrm{C}\right)=6,20$ dias

Adotar duas lagoas de maturação em série.

profundidade, $\mathrm{H}=1,00 \mathrm{~m}$ (adotado)

TDHan $=2$ dias

TDHfac $=6,86$ dias

$\mathrm{TDH}$ mat $=4$ dias (adotado para cada lagoa)

Número de Coliformes termotolerantes efluentes, considera-se o fluxo disperso:

$N e f=\frac{N a f}{(1+k t x T D H a n) x(1+k t x T D h f a c) x(1+k t x T D H m a t)^{2}}$

$N e f=\frac{10^{8}}{(1+6,20 \times 2) x(1+6,20 \times 6,86) x(1+6,20 \times 4)^{2}}=>N e f=257,55 \mathrm{CTT} / 100 \mathrm{ml}$

Cálculo do volume, para um $\mathrm{TDH}=4$ dias (adotado para cada lagoa):

$V=Q t=\frac{2052,988 \mathrm{~m}^{3}}{\text { dia }} * 4$ dias $=8211,952 \mathrm{~m}^{3}$

Área para cada lagoa de maturação:

$A=\frac{V}{h}=\frac{8211,952 \mathrm{~m}^{3}}{1 \mathrm{~m}}=8211,952 \mathrm{~m}^{2}=0,82 \mathrm{ha}$

Área total lagoas de maturação: 2 x $8211,952 \mathrm{~m}^{2}=16423,904 \mathrm{~m}^{2}=1,64$ ha

Dimensões:

Com uma área de $8211,952 \mathrm{~m}^{2}$, as possíveis dimensões são, com relação L/B=2,5; comprimento 143,26 m e largura $57,32 \mathrm{~m}$. Adotando uma profundidade $\mathrm{h}=1 \mathrm{~m}$.

As lagoas vão ter uma inclinação de talude interno vai ser 1:2,5. Logo:

Comprimentos

Comprimento de fundo $=\mathrm{L}-\mathrm{d} \cdot \mathrm{h}=143,26-(2,5 \mathrm{X} 1)$

Comprimento de fundo $=140,76 \mathrm{~m}$

Comprimento no nível da água $=\mathrm{L}+\mathrm{d} . \mathrm{h}=143,26+(2,5 \mathrm{X}$ 1)

Comprimento no nível da água $=145,76 \mathrm{~m}$

Comprimento na crista do talude $=$ comprimento no nível da água +2 .d.(borda livre) 


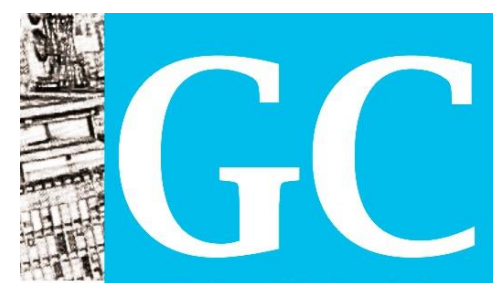

Revista Nacional de

Gerenciamento de Cidades

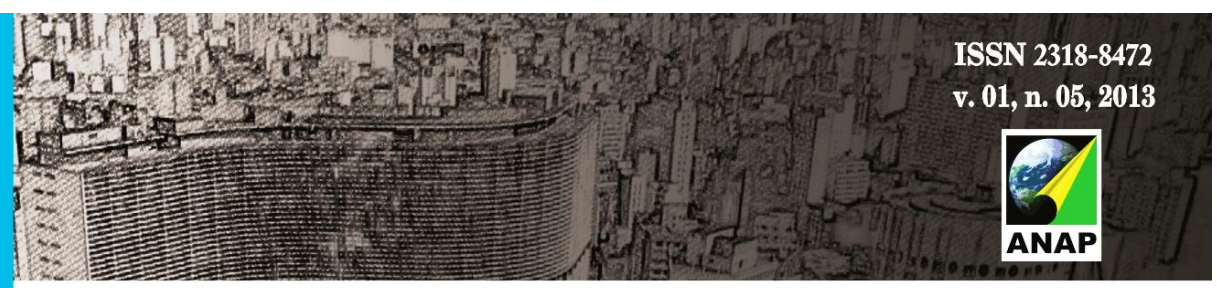

Comprimento na crista do talude $=145,76+2$ X 2,5 X 0,6

Comprimento na crista do talude $=148,76 \mathrm{~m}$

Larguras

Largura de fundo $=\mathrm{B}-\mathrm{d} \cdot \mathrm{h}=57,32-(2,5 \times 1)$

Largura de fundo $=54,82 \mathrm{~m}$

Largura no nível da água $=\mathrm{B}+\mathrm{d} . \mathrm{h}=57,32+(2,5 \mathrm{X} 1)$

Largura no nível da água $=59,82 \mathrm{~m}$

Largura na crista do talude $=$ largura no nível da água +2 .d.(borda livre)

Largura na crista do talude $=59,82+2 \times 2,5 \times 0,6$

Largura na crista do talude $=62,82 \mathrm{~m}$

Área do sistema de lagoas

Área $=\mathrm{A}_{\mathrm{an}}+\mathrm{A}_{\mathrm{fac}}+\mathrm{A}_{\mathrm{mat}}=821,19 \mathrm{~m}^{2}+7038,74 \mathrm{~m}^{2}+16423,904 \mathrm{~m}^{2}=24283,834 \mathrm{~m}^{2}=2,43 \mathrm{ha}$

Área necessária para construção considerando o fator de 1,2 :

Área construção: Área total x 1,2=2,43 x 1,2=2,91ha $\approx 3,00 \mathrm{ha}$

Área per capita $=\left(27752,98 \mathrm{~m}^{2} / 17.252 \mathrm{hab}\right)=1,61 \mathrm{~m}^{2} / \mathrm{hab}$

Remoção de DBO no sistema:

ANAERÓBIO+FACULTATIVA SECUNDÁRIA $=85,14 \%$

$\mathrm{DBO}_{\text {afluente }}=300 \mathrm{mg} / \mathrm{l} \times 0,1486=44,58 \mathrm{mgDBO} / \mathrm{l}$

Mat $1(25 \%$ remoção $)=44,58 \mathrm{mg} / 1 \times 0,75=33,43 \mathrm{mgDBO} / 1$

Mat $2(25 \%$ remoção $)=33,43 \mathrm{mg} / 1 \times 0,75=25,07 \mathrm{mgDBO} / \mathrm{l}$ (Efluente final)

Efluente final de $\mathrm{DBO}_{5}$ filtrado $=\mathrm{DBO}_{5 \text { total }} \times 0,4 *$

Efluente final de $\mathrm{DBO}_{5}$ filtrado $=25,07 \times 0,4 *=10,03 \mathrm{mgDBO} / \mathrm{l}$

*As algas no efluente $=$ mínimo $60 \%$ de $\mathrm{DBO}_{5} *$ total

Eficiência lagoa de maturação

$E=\frac{N 0-N}{N 0} \times 100=\frac{10^{8}-257,55}{10^{8}} \times 100=99,99 \%$

Remoção de ovos helmintos

Considerando afluente $=300$ ovos $/ 1$

Lagoa anaeróbia

Ean $=100 x\left[1-0,41\left(e^{-0,49 t+0,0085 t^{2}}\right)\right]$

Ean $=100\left[1-0,41 e^{-0,49 * 2+0,0085 * 4}\right]$

Ean $=84,08 \%=>C e=C o *\left(1-\frac{\text { Ean }}{100}\right)=300 \frac{\text { ovos }}{l} *\left(1-\frac{84,08}{100}\right)=47,76$ ovos $/ l$

Lagoa facultativa

$E f a c=100 x\left[1-0,41\left(e^{-0,49 t+0,0085 t^{2}}\right)\right] \Rightarrow$ Ef $a c=100 x\left[1-0,41\left(e^{-0,49 * 6,86+0,0085 * 47,06}\right)\right]=>E f a c=97,88 \%$

Ce $=\operatorname{Co} *\left(1-\frac{E f a c}{100}\right)=47,76 \frac{\text { ovos }}{l} *\left(1-\frac{97,88}{100}\right)=1,01$ ovos $/ l$

Efluente final do sistema:

Emat $=100 x\left[1-0,41\left(e^{-0,49 t+0,0085 t^{2}}\right)\right] \Rightarrow$ Emat $\left.=100 x\left[1-0,41 e^{-0,49 * 4+0,0085 * 16}\right)\right]=>$ Emat $=93,38 \%$

$C e=C o *\left(1-\frac{\text { Emat }}{100}\right)=1,01 \frac{\text { ovos }}{l} *\left(1-\frac{93,38}{100}\right)=0,06$ ovos $/ l$

Reuso do efluente:

População urbana em 2011= 14.000 habitantes

População urbana em $2031=17.252$ habitantes

$\mathrm{Q}=2052,988 \mathrm{~m}^{3} / \mathrm{dia}$

A população em 2011 é de 20.000 habitantes, sendo $70 \%$ urbana, então:

$\mathrm{Q}=2052,988 \mathrm{~m}^{3} / \mathrm{dia} \times 14.000 / 17.252=1.666 \mathrm{~m}^{3} / \mathrm{dia}$

Estima-se o nível de irrigação $=5 \mathrm{~mm} /$ dia

Área disponível para irrigar $=\left(1.666 \mathrm{~m}^{3} / \mathrm{dia}\right) / 0,005 \mathrm{~m} / \mathrm{dia}=333.200 \mathrm{~m}^{2}=33,32$ ha

Se o nível de irrigação $=10 \mathrm{~mm} /$ dia

Área disponível para irrigar $=\left(1.666 \mathrm{~m}^{3} / \mathrm{dia}\right) / 0,01 \mathrm{~m} / \mathrm{dia}=166.600 \mathrm{~m}^{2}=16,66 \mathrm{ha}$

Perdas do sistema via evaporação na superfície das lagoas $=5 \mathrm{~mm} /$ dia

Área do sistema de lagoas: Área total x 1,2=2,43 x1,2=2,91 ha= $29.160 \mathrm{~m}^{2}$

Agua perdida $=29.160 \mathrm{~m}^{2} \times 0.005 \mathrm{~m}=145,8 \mathrm{~m}^{3} / \mathrm{dia}$ 

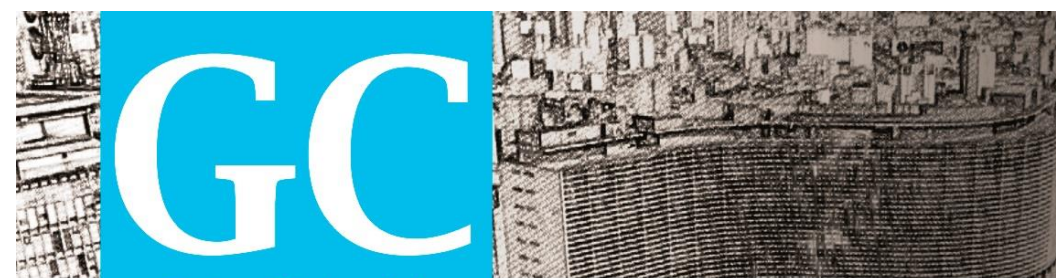

Revista Nacional de

Gerenciamento de Cidades

$=145,8 \mathrm{~m}^{3} / \mathrm{dia} / 1.666 \mathrm{~m}^{3} /$ dia $\times 100=8,75 \%$ de água perdida

Área de irrigação disponível, considerando as perdas:

Área de irrigação $(5 \mathrm{~mm} / \mathrm{dia})=33,32$ ha $\times 0.9112=30,36$ ha

Área de irrigação $(10 \mathrm{~mm} / \mathrm{dia})=16,66$ ha $\times 0,9112=15,18$ ha

Fonte: Autor (2013)

\section{RESULTADOS E DISCUSSÃO}

O projeto foi concebido de forma modular sendo composto por pré-tratamento (gradeamento de barras paralelas, para remoção de sólidos grosseiros, seguido pela caixa de areia, cuja finalidade é reter sólidos de menor diâmetro) e para a estação do presente projeto, será instalado um medidor Parshall a jusante da caixa de areia, acoplado a uma régua graduada para leitura das lâminas de líquido, e respectivas vazões, seguido de quatro lagoas de estabilização (anaeróbia, facultativa secundária e lagoas de maturação) como mostra a Figura 2. Quando houver desnível suficiente entre a rede de coleta de esgotos e a entrada do sistema propriamente dito é preferível que esta se dê por ação da gravidade; a instalação de uma estação elevatória de esgotos se faz necessária quando não houver cota suficiente para que a entrada do esgoto se dê por ação da gravidade.

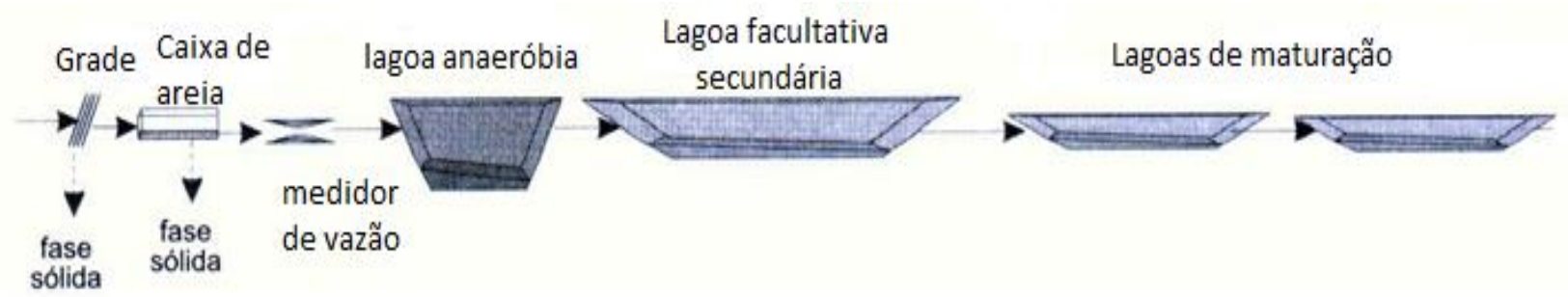

Figura 2. Esquema do projeto proposto para a Estação de Tratamento de Efluentes-ETE. Fonte: Autor (2013)

\section{Gradeamento}

A inclinação da barra deve ser entre $70^{\circ}$ e $90^{\circ}$ para que ocorra maior rendimento evitando-se que o material desprenda-se facilmente do rastelo. A velocidade de passagem nas grades $(\mathrm{v})$ deverá ficar entre $0,40 \mathrm{~m} / \mathrm{s}$ e $0,75 \mathrm{~m} / \mathrm{s}$, adotando-se $0,60 \mathrm{~m} / \mathrm{s}$. E 


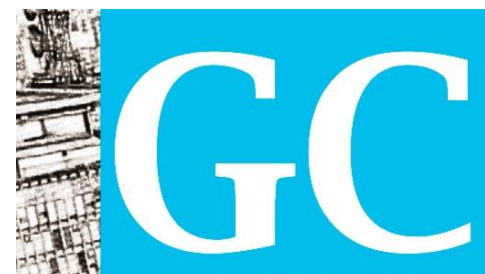

Revista Nacional de

Gerenciamento de Cidades
ISSN 2318-8472

v. 01, n. 05,2013

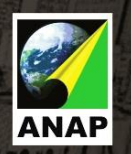

a obstrução máxima da grade deverá ser de 50\%. A Figura 3 mostra as dimensões encontradas para a grade:

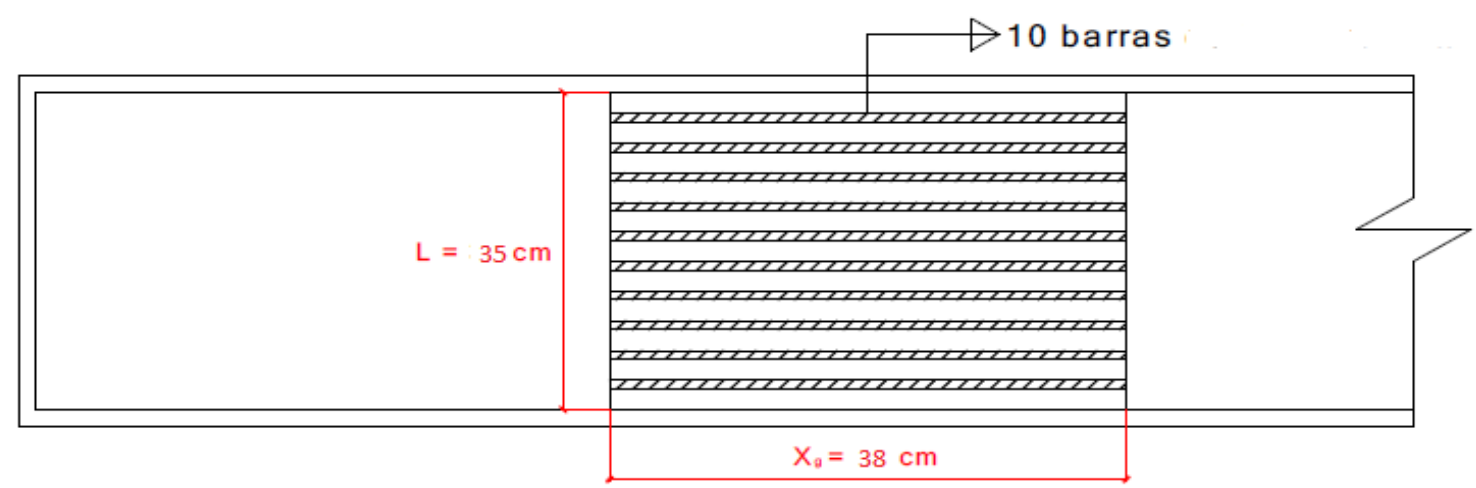

Figura 3. Detalhamento da unidade de gradeamento. Fonte: Autor (2013)

\section{Desarenador e medidor Parshall}

De acordo com a NBR-12209, a limpeza do desarenador deve ser mecanizada, pois a vazão máxima é superior a $250 \mathrm{l} / \mathrm{dia}$. As calhas Parshall constituintes de uma ETE possuem dimensões predefinidas e sua escolha dependente das vazões mínima e máxima de projeto, a calha que atende as vazões do projeto é a $W=3$ " (AZEVEDO NETTO et al., 1998). A velocidade de passagem nas grades (v), deverá ficar entre 0,40 $\mathrm{m} / \mathrm{s}$ e $0,75 \mathrm{~m} / \mathrm{s}$, adotando-se $0,60 \mathrm{~m} / \mathrm{s}$, a obstrução máxima da grade $=50 \%$, deve-se manter velocidade no desarenador em 0,30 m/s. (variação mínima de 20\% - 0,24 a 0,36 $\mathrm{m} / \mathrm{s}$ ). As dimensões encontradas podem ser observadas conforme a Figura 4.

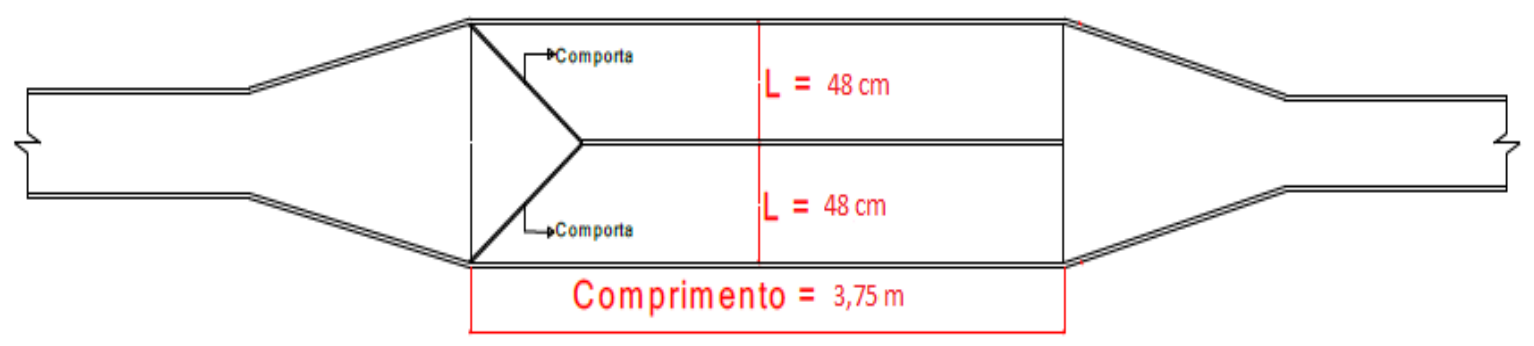

Figura 4. Detalhamento da caixa de areia. Fonte: Autor (2013) 


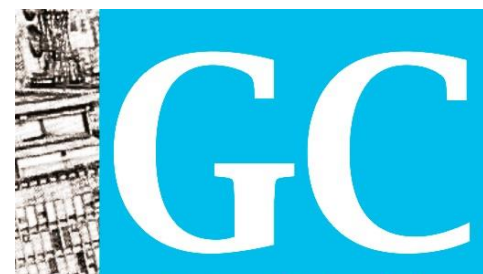

Revista Nacional de

Gerenciamento de Cidades
ISSN 2318-8472

v. 01, n. 05, 2013

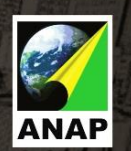

Para a largura encontrada de 3", temos as demais dimensões obtidas conforme Azevedo Netto et al. (1998). A Figura 5 mostra as dimensões da calha Parshall.

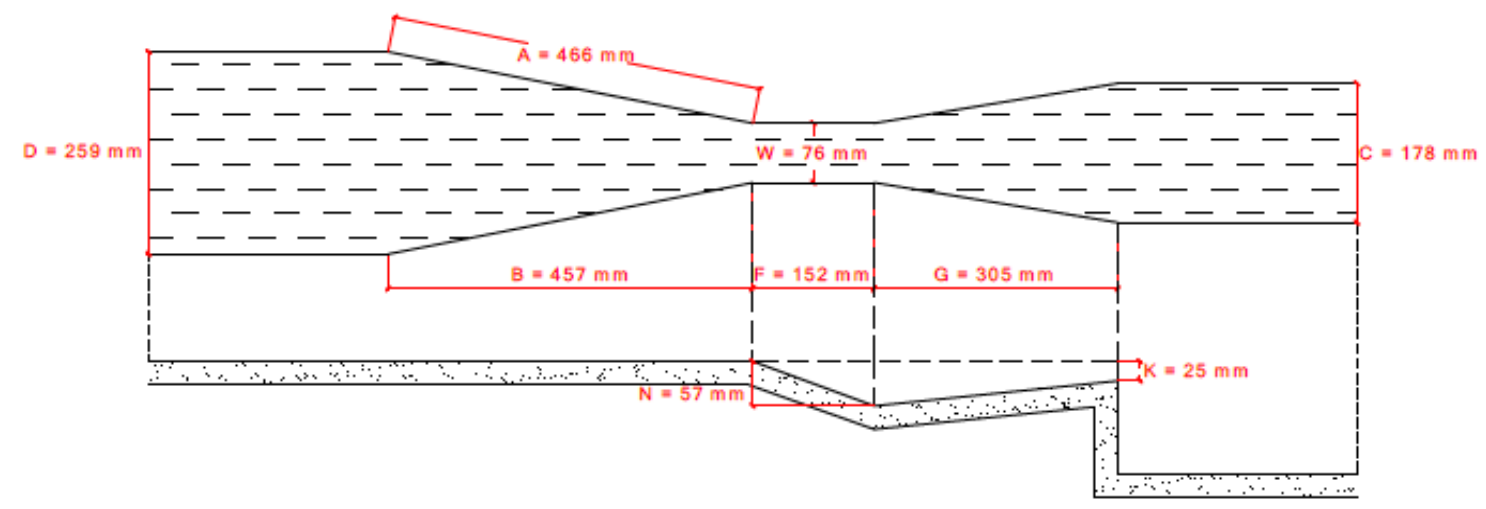

Figura 5. Detalhamento da calha Parshall. Fonte: Autor (2013)

\section{Lagoa anaeróbia}

As lagoas anaeróbias são normalmente empregadas para estabilização de altas cargas orgânicas aplicadas e atuam como unidade primária em um sistema em série de lagoas. Sua função principal é a degradação da matéria orgânica Demanda Bioquímica de Oxigênio- DBO e Demanda Química de Oxigênio- DQO envolvendo a participação de bactérias facultativas e estritamente anaeróbias. A temperatura usada no projeto vai ser de $25^{\circ} \mathrm{C}$, a concentração de DBO do afluente é de $300 \mathrm{mg} / \mathrm{L}$ (adotada). De acordo com o dimensionamento, a lagoa anaeróbia tem-se as seguintes dimensões, Figura 6.

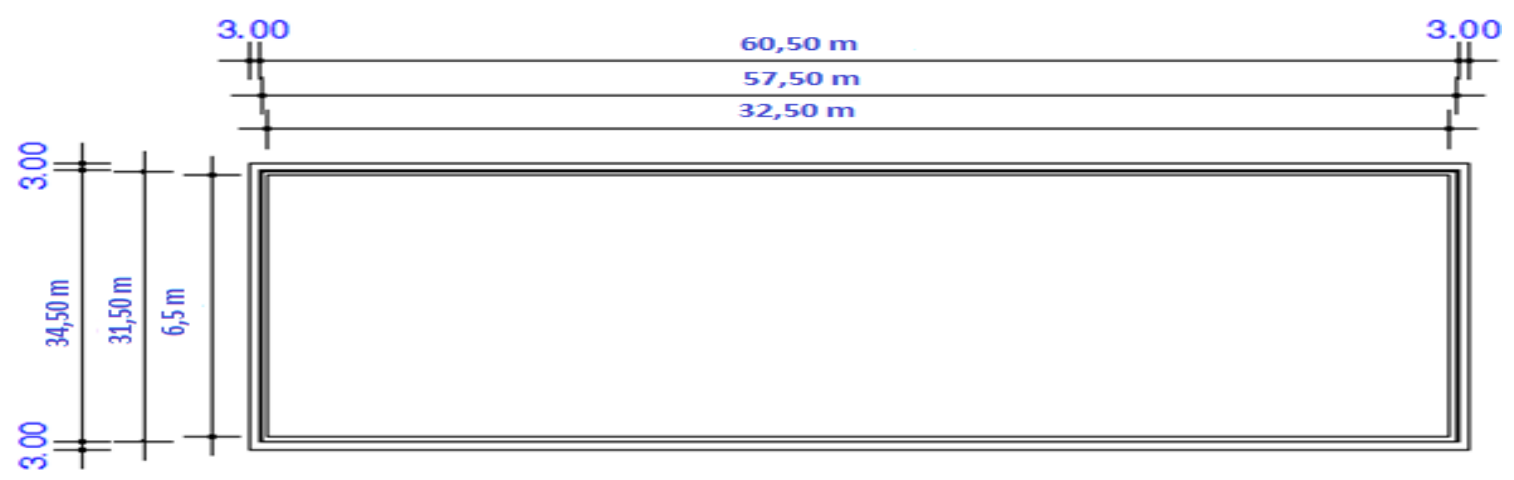

Figura 6. Detalhamento da Lagoa anaeróbia. Fonte: Autor (2013) 


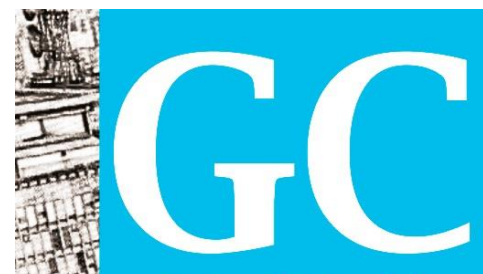

Revista Nacional de

Gerenciamento de Cidades

\section{Lagoa facultativa secundária}

A carga afluente é o efluente da lagoa anaeróbia, como a eficiência de remoção na lagoa anaeróbia é de 60\%, a carga afluente a lagoa facultativa é de 246,35 kg de DBO/d. Para climas quentes e altas insolações e radiações solares como o nordeste brasileiro, pode ser usada uma taxa bem alta, considerando-se a lagoa facultativa secundária, temse segundo Mara et al. (1986) para T=25ํㅡ, uma taxa de aplicação superficial de $350 \mathrm{Kg}$ de DBO/ha.d. A Figura 7 apresenta as dimensões da lagoa facultativa secundária.

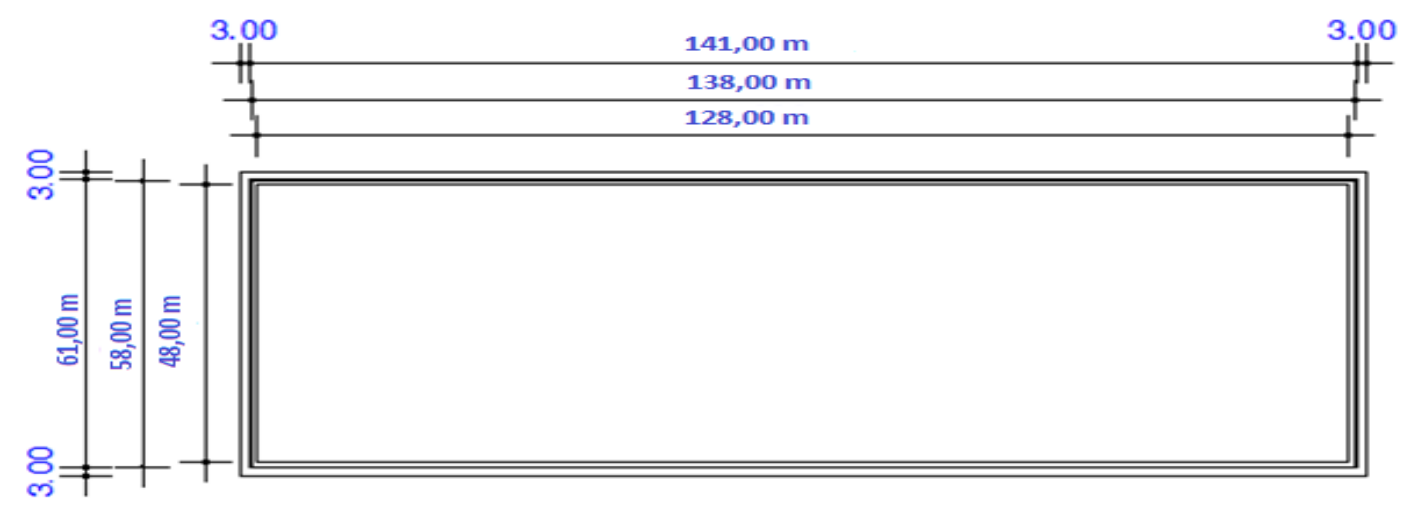

Figura 7. Detalhamento da Lagoa Facultativa Secundária. Fonte: Autor (2013)

\section{Lagoa de maturação}

As lagoas de maturação são predominantemente aeróbias, em virtude da remoção de grande parte da carga orgânica nos tratamentos precedentes, tendo como objetivo principal a remoção de organismos patogênicos e de nutrientes. A Figura 8 mostra as dimensões das lagoas de maturação. 


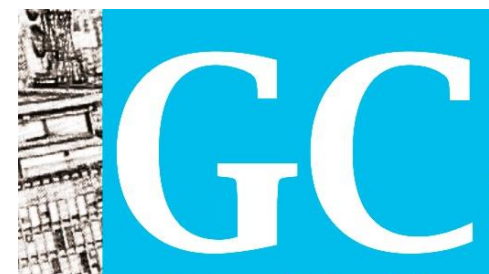

Revista Nacional de

Gerenciamento de Cidades
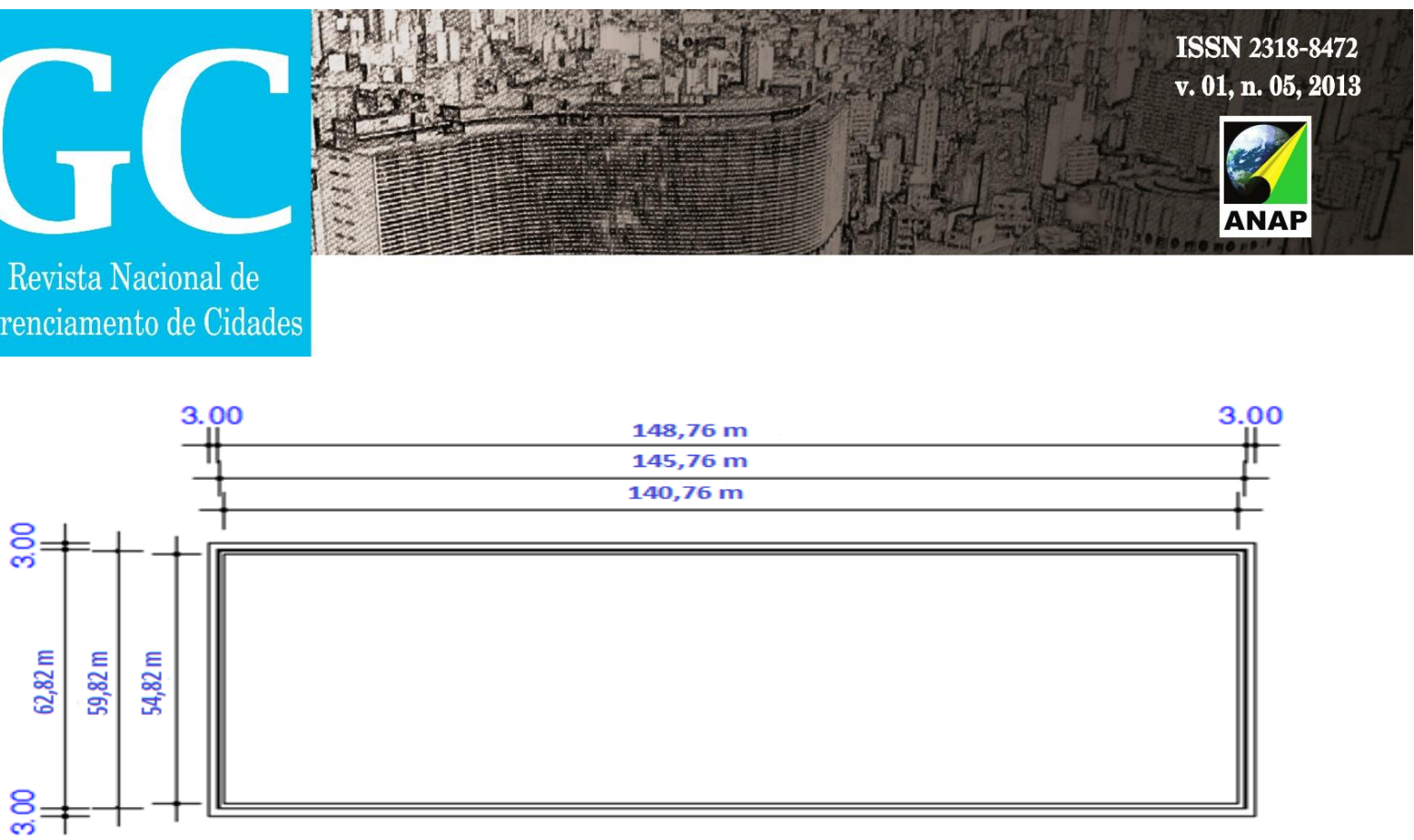

Figura 8. Detalhamento das lagoas de maturação. Fonte: Autor (2013)

A entrada do afluente na lagoa deve satisfazer às seguintes condições: garantir uma ampla homogeneização do líquido; ser submersa, de forma a não possibilitar o desprendimento de gases mal cheirosos e evitar o solapamento dos taludes e do fundo da lagoa. A saída do efluente da lagoa deve levar em consideração os seguintes aspectos: situar-se na extremidade oposta à da entrada, para evitar curtos-circuitos; não deve situar-se no mesmo alinhamento da entrada; podem ser de nível fixo ou variável; possuir placas defletoras com alcance abaixo do nível d'água e fácil acesso para permitir a medição de vazões. A Figura 9 apresenta os dispositivos de entrada e saída das lagoas projetadas.
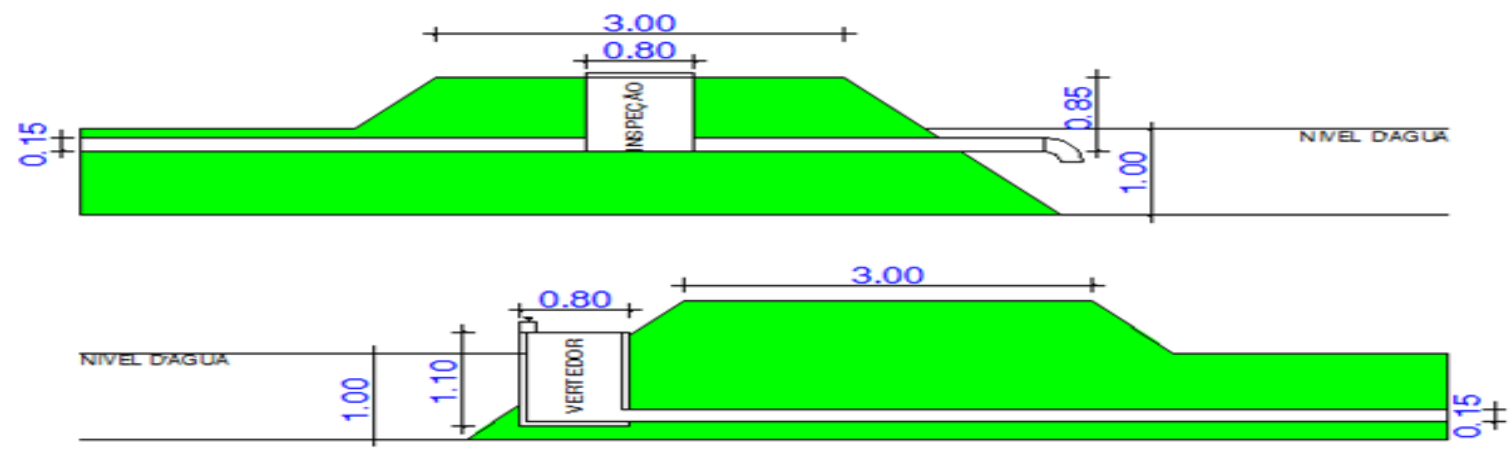

Figura 9. Detalhamento- dispositivos de entrada e saída das lagoas. Fonte: Autor (2013)

Conforme o dimensionamento proposto, o número de coliformes termotolerantes no efluente final corresponderá a 257,55 UCT/100ml a remoção de ovos helmintos 0,06 ovos/l, logo o sistema proposto deverá atender as diretrizes da World Health Organization- WHO (2006), para irrigação irrestrita. O esgoto da cidade de 20.000 

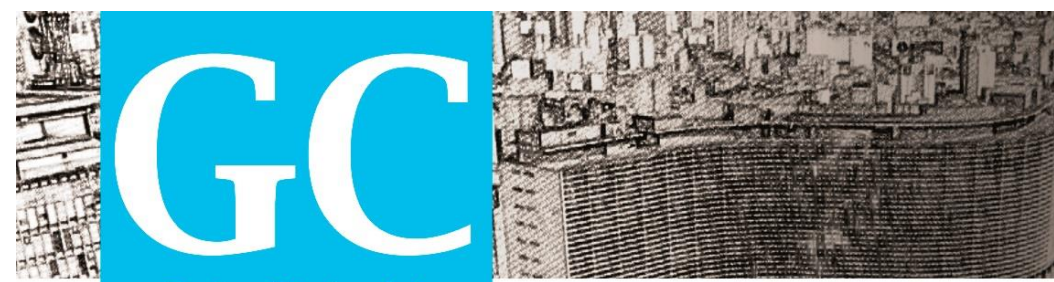

Revista Nacional de

Gerenciamento de Cidades

habitantes pode suportar um projeto de irrigação de 15,18 ha - 30,36 ha em 2011 (14.000 habitantes), ampliando para 18,71 ha - 36,50ha em 2031 (17.252 habitantes), levando-se em consideração a evaporação do sistema de $5 \mathrm{~mm} /$ dia e $10 \mathrm{~mm} /$ dia, respectivamente.

\section{CONCLUSÕES}

As características similares de clima e escassez de água que existem entre Israel e a região do semiárido do nordeste brasileiro podem, em princípio, levar a crer que a experiência bem sucedida deste país, no campo da agricultura irrigada, utilizando águas residuais, poderá ser facilmente repetida no Brasil.

No processo sugerido o esgoto é tratado em lagoas artificiais (taludes de terra), onde as algas promovem a aeração e as bactérias, a transformação da matéria orgânica. Juntas elas proporcionam o necessário equilíbrio ao sistema, ou seja, uma biodegradação compatível com o oxigênio produzido pelas algas (NETO, 1997; D’AVIGNON et al., 2002).

O financiamento público é justificável, devido à poupança resultante dos gastos com a saúde pública e com outras externalidades, investimentos em saneamento, além de proporcionar os benefícios relacionados à salubridade, tendem a instigar 0 desenvolvimento socioeconômico da região. Em períodos de chuvas, como a irrigação é desnecessária as águas residuais tratadas podem ser lançadas em um manancial sem danos ao meio ambiente, de acordo com a resolução CONAMA nº. 430 de 13 de maio 2010 que dispõe sobre as condições e padrões de lançamento de efluentes.

\section{REFERÊNCIAS}

ALVAREZ, H. R. El valle de Mezquital. México: Estudio de caso VII. Disponível em : htpp://www.cepis.ops-oms.org/eswww/projeycto/repedisv/publica. Acesso em 28 de agosto de 2011.

ANGEKALIS, A.N. MARECOS, DO MONTE, M.H.F. BONTOUX, L.; ASANO T. The status of wastewater reuse ppratice in the Mediterranean basin need for guidelines. Water Resources, Bethesda, v, 33, p. 2201-2217, 1999. 

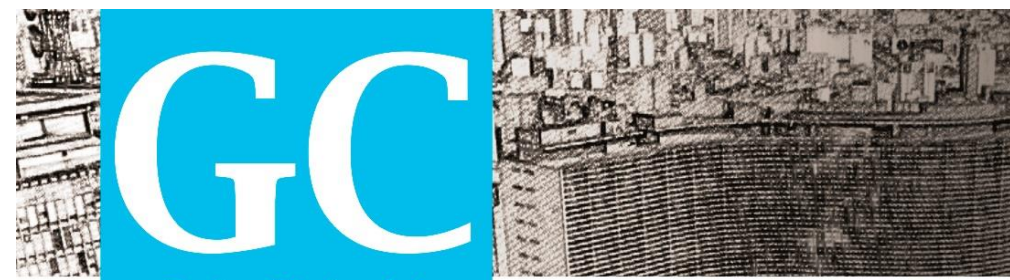

Revista Nacional de

Gerenciamento de Cidades

AZEVEDO NETTO, J. M, (et al). Manual de hidráulica. 8 ed. São Paulo: Edgar Bucher, 1998.

BAHRI, Akissa. Water reclamation and reuse criteria. In: ASANO, Takashi. Water quality management library - Volume 10/Wastewater reclamation and reuse. Pennsylvania, USA: Technomic Publication, 1998.

CONAMA. Resoluções do conselho nacional do meio a mbiente, Leis, etc. Brasília: SEMA, 2011.

D’Avignon, A. (ed) (2002). Manual de auditoria ambiental para estações de tratamento de esgotos domésticos. Rio de Janeiro, Qualitymark.

GARCIA, H. C. \& GARAVELO, T. M.. Geografia do Brasil: dinâmica e contrastes. São Paulo: Scipione, 1996.

INSTITUTO BRASILEIRO DE GEOGRAFIA E ESTATÍSTICA. Coordenação de População e Indicadores Sociais. Perfil dos Municípios Brasileiros. Rio de Janeiro: IBGE, 2011.

MARA, D. D., PEARSON, H. Artificial freshwater environmental: Waste stabilization ponds. In Biotechology, v. 8, p. 177-206, 1986.

NETO, C. O. ANDRADE (1997). Sistemas simples para tratamento de esgotos sanitários: experiência brasileira. Rio de Janeiro, ABES.

ODENDAAL, P.E., et al. Wastewater reuse in South Africa. Wastewater Reclamation and Reuse. T. Asano (Ed.), Water Quality Management Library v. 10, Technomics Publishing, 1998

VAN DER HOEK, W. Urban wastewater: a valuable resource for agriculture. A case study from Horoonabad, Pakistan. Colombo, Sri Lanka: International Water Management Institute, 2002. 29 p. (Research Report, 63).

VON SPERLING, M. (1996). Introdução à qualidade das águas e ao tratamento de esgotos. Belo Horizonte, Universidade Federal de Minas Gerais. (Princípios do tratamento biológico de águas residuárias).

WHO. WHo Guidelines for the safe use of wastewater excreta and greywater. Wastewater and excreta use in aquaculture, WHo, unep, Genebra, Suíça, 2006. v.III. 